\title{
Nutritional components affecting skeletal development in fish larvae
}

\author{
Chantal Cahu $u^{\mathrm{a},{ }^{\star}}$, José Zambonino Infante $^{\mathrm{a}}$ and Toshio Takeuchi ${ }^{\mathrm{b}}$
}

a : Unité Mixte INRA IFREMER de Nutrition des Poissons, B.P. 70, 29280 Plouzané, France

b : Department of Aquatic Biosciences, Tokyo University of Fisheries, Minato, Tokyo 108-8477, Japan

*: Corresponding author : Tel. : +33-2-9822-4403; fax: +33-2-9822-4653 ; Chantal.Cahu@ifremer.fr

\begin{abstract}
:
Marine fish larvae undergo major functional and morphological changes during the developmental stages and several factors can interfere with the normal development of larvae and affect fry quality. Skeletal malformations, such as spinal malformation-scoliosis, lordosis, coiled vertebral column-, missing or additional fin rays, bending opercle or jaw malformations, are frequently observed in hatchery-reared larvae. This paper reviews the effects of some nutritional components on skeletal development in larvae of a number of fish species. In the dietary lipid fraction, for instance, it was proven that the phospholipid concentration affected the spinal malformation rate in sea bass fed a compound diet from mouth opening onwards. Phosphatidylinositol, in particular, seems to prevent skeletal deformities. Highly unsaturated fatty acids, and particularly DHA enrichment in live prey, induce a decrease of opercular deformities in milkfish. It is known that highly unsaturated fatty acids have profound effects on gene expression, leading to changes in metabolism, growth and cell differentiation, and these effects are worth investigating in developing fish. The nature of the dietary protein fraction also affects the quality of fish larvae development. It appears that dietary incorporation of 20 amino acid peptides or di- and tripeptides leads to a reduction of spinal malformations in sea bass. Among vitamins, the teratogenic effect of retinoic acid is now well documented in vertebrates. High dietary retinoic acid levels result in higher incidence of bone deformities, such as vertebral curvature, central fusion and compression of vertebra in Japanese flounder larvae. The teratogenic effect of retinoic acid observed in embryonic and postembryonic stages was explained by a depression of shh expression. As for vitamin C, opercular abnormalities in milkfish larvae, associated with distortion of gill filament cartilages, were reduced by $50 \%$ when feeding larvae with ascorbic acid enriched rotifers and Artemia, compared to control fish.
\end{abstract}

Keywords: Fish larvae; Quality; Skeletal development; Peptides; Phospholipid; Amino acid; Ascorbic acid; Retinoic acid 


\section{Introduction}

Marine fish larvae undergo major functional and morphological changes during the developmental stages. Several factors can interfere with the normal development of larvae and affect larvae quality. The quality in marine fish larvae can be defined as a normal body conformation and an aptitude to continue their development until juveniles and adult stages.

Several physical anomalies have been described in fish larvae. In a recent study, Boglione et al. (2001) showed that only 4\% of wild caught animals are affected by body deformations. This percentage can reach very high values in hatchery-reared larvae (Divanach et al., 1996). Malformations are often associated with growth depression and high mortality rate. Andrades et al. (1996) showed that only a few percent of larvae affected by skeletal (lordotic) malformation can survive after larval development. This leads to significant loss of money for the hatchery. In addition, fish growing with malformations are sold at a depressed price.

Different types of abnormalities have been described. In round fish, such as sea bass, sea bream or milkfish, a lot of skeletal malformations have been observed in hatchery-reared larvae. Spinal malformation as scoliosis, lordosis, coiled vertebral column, missing or additional fin rays, and also bending opercle or jaw malformations have been described (for review, see Divanach et al., 1996). Flat fish, as turbot or Japanese flounder are mainly affected by problem of pigmentation (Estevez et al., 1999, Takeuchi, 2001). Beside morphological malformations, quality can also be negatively affected by a low stress resistance in fish larvae reared in hatchery (Fushimi, 2002, Koven et al., 2001).

Several factors have been evoked to explain skeletal deformities in fish larvae reared in hatchery. Lordosis in sea bass and sea bream, mainly affecting vertebrae 14-15, has been related to the hydrodynamic in tanks, particularly the water current intensity (Chatain, 1994). Inadequate light intensity as well as temperature and salinity in rearing water have been reported as sources of skeletal malformations (Johnson and Katavic, 1984). Pathology in very young larvae, and especially development of some pathogenic bacteria can induce high rates of malformations (Madsen and Dalsgaard, 1999). Moreover, it has been shown that prevalence of skeletal malformations, including jaw deformities, is significantly higher in triploid farmed fry of Atlantic salmon (Sadler et al., 2001). But recent data give more and more evidences of an important role of several components of diet fed to larvae during early 
stages. Indeed, nutritional requirement of fish larvae for sustaining growth and survival become to be known, and recent experiments in fish larvae nutrition are now aimed to improve larvae quality. Some experiments were conducted with live prey, and gave indications on effects of lipo-soluble nutrients, such as fatty acids or some vitamins, on larvae quality. But compound diets now used at experimental scale in early stages of marine fish allowed more accurate experiments to study effects of other components, such as peptides.

This paper is aimed to review the effects of some nutritional components on skeletal development in marine fish larvae.

\section{Effect of dietary lipidic fraction}

\subsection{Phospholipid}

From early 1980’s, Kanazawa et al. (1983) showed that fish larvae have a more specific phospholipid requirement compared to juvenile fish. Indeed, fish are able to synthesize phospholipid, but it has been suggested in several species that the synthesis is not sufficient to meet larvae requirement during a period of high cell multiplication. These authors showed that the rock bream, Oplegnathus fasciatus, require 5\% phospholipid related to diet dry matter during larval stages, while 3\% phospholipid are sufficient for juvenile stages. Kanazawa et al. (1981) also showed that dietary incorporation of phospholipid reduced malformation, especially twist of jaw and scoliosis, in Ayu larvae, Plecoglossus altivelis. The experiment was conducted by feeding Ayu larvae both rotifers and compound diet containing chicken egg lecithin.

Recently, an experiment was conducted in sea bass (Dicentrarchus labrax) fed compound diet from mouth opening (Cahu et al., in press). Four experimental diets, isoenergetic and isoproteinic, were formulated, differing only in an increasing level of soy bean lecithin and decreasing level of fish oil (Table 1). So phospholipid level increased from $2.7 \%$ of dry matter in PL3 diet to 11.6\% in PL12 diet. Larval growth and survival was very low in the group fed the diet incorporating 2.7\% phospholipid: weight reached only $2 \mathrm{mg}$ at day 40 post hatching and survival was only $22 \%$ of the initial number. In the group fed the diet containing $11.6 \%$ phospholipid, larvae final weight reached $32 \mathrm{mg}$, and survival was $73 \%$ at day 40 posthatching. 
But the most interesting result concerned malformation. Spinal malformations and jaw deformities, were assessed at day 40, by binocular observation on 100 larvae for each dietary group (Fig. 1). 35\% of larvae fed the diet incorporating the lowest phospholipid level exhibited malformation, whereas only $2 \%$ of larvae fed the diet containing $11.7 \%$ phospholipid exhibited malformations. Geurden et al. $(1997,1998)$ reported that the different phospholipid classes highly affect growth and development in a freshwater species, carp (Cyprinus carpio). In particular, they concluded that phosphatidylcholine has a growth promoting effect, and phosphatidylinositol prevents skeletal deformities. Carp larvae fed a diet incorporating 1.3\% phosphatidylinositol related to diet dry matter exhibited very low deformity rate ( $2 \%$ of total larvae) compared to larvae fed diet incorporating the same level of phosphatidylcholine (32\% of total larvae). Our experiment in sea bass suggests that a level of $1.6 \%$ phosphatidylinositol in diet used from first feeding is convenient for preventing deformities during sea bass development. The effect of phosphatidylinositol on larvae development is not yet well understood. But is known that phosphatidylinositol has a rich diversity of forms and functions within the cell. Apart from its structural role as part in membrane, it is a precursor of second messengers regulating calcium entry in cell and is a membrane anchor for a great variety of cell surface proteins. Phosphatidylinositol is involved in a signalling system controlling biological processes in early development in vertebrates (Berridge and Irvine, 1989).

\subsection{Highly unsaturated fatty acids}

It is now well known that highly unsaturated fatty acid, mainly eicosapentaenoic acid (EPA) docohexaenoic acid (DHA) and arachidonic acid (ARA) are essential for growth, development and survival in marine fish (for review see Sargent et al., 1999). Beside their growth promoting effect, EPA and mainly DHA are involved in the development of the nervous system, including brain and visual cell (Furuita et al., 1998), and pigmentation development in flat fish (Reitan et al., 1994, Shields et al. 1999). They also improve vitality and stress resistance (Watanabe and Kiron, 1994). A recent study also evidenced that dietary incorporation of DHA induces a decrease of opercular deformities in milkfish Chanos chanos (Gapasin and Duray, 2001). Milkfish larvae were fed during 25 days live prey, rotifer and Artemia, either enriched or not with DHA. Larvae were afterwards reared extensively in

fertilised ponds and the incidence of opercular deformities was assessed in 85-day-old 
fingerlings. It appeared that opercular deformity was 50\% reduced in the group receiving DHA enriched live prey, compared to the other group (17\% and 33\% respectively).

The effect of fatty acids, and especially DHA, on development begins to be understood in mammals and amphibians (Jump and Clarke, 1999). Dietary fat has profound effects on gene expression, leading to changes in metabolism, growth and cell differentiation. Fatty acids, and especially highly unsaturated fatty acids, act on the genome through specific nuclear receptors, such as Peroxisome Proliferator Activated Receptors (PPAR). This receptor binds DNA as a heterodimer with the retinoid $\mathrm{X}$ receptor ( $\mathrm{RXR})$. RXR regulates genes that are involved in skeletal development during ontogenesis. So, we can assume that highly unsaturated fatty acids can affect by this way the skeletal formation during development. The dietary fat regulation of gene expression is extensively studied in mammals, as it has wide implication in human health. This regulation needs to be investigated in developing fish.

\section{Effect of dietary proteinic fraction}

\subsection{Effect of amino acids}

Little work has been done on amino acid requirements of fish larvae, largely due to the absence, until a recent date, of formulated diets sustaining larval growth. Nevertheless, a large quantity of amino acid is necessary for sustaining the efficient protein synthesis and the rapid growth rate in fish larvae (Rønnestad et al., 1999). By using live prey having different amino acid profiles, Conceição et al. (1997) showed that leucine and taurine, and its precursors methionine and cysteine, may limit growth in turbot larvae. In the same way, the comparison of amino acid profile between live prey and fish larvae suggest that methionine, tyrosine, isoleucine and valine in the rotifers do not meet the nutritional requirement of sea bream and sole. Methionine would be the limiting amino acid for growth in fish larvae fed rotifers (Aragão et al., 2001).

Moreover, it has been reported that a deficiency of the amino acid tryptophan induces scoliosis in salmonids, such as sockeye salmon, rainbow trout and coho salmon, and chum salmon (Akiyama et al., 1986). Akiyama et al. (1986) conducted an experiment by feeding chum salmon fry during the 4 first weeks of their life with a tryptophan deficient diet. 
$57 \%$ of total fry was affected by scoliosis at this time. After this period, fish were divided into 4 groups (Fig.2): one group fed the same tryptophan deficient diet, one group fed a diet supplemented with tryptophan and two groups fed diets supplemented with two serotonin levels. Serotonin is one of the tryptophan metabolites. It is a brain neurotransmitter and it has been shown that serotonin affects the functions of muscle in mammals. It was hypothezised by the authors that scoliosis observed in salmonids could be induced by an abnormal muscular contraction. After 3 weeks of feeding, scoliosis incidence increased in the group still fed on tryptophan deficient diet, up to $80 \%$. The scoliosis incidence decreased to $18 \%$ in the group refed with a diet incorporating $0.24 \%$ tryptophan. It can be pointed out that the spinal deformity was cured rapidly, from the first week, in fish fed this diet. But scoliosis incidence still increased in the group fed diet incorporating low and high serotonin level. So, dietary serotonin did not prevent scoliosis emergence. The scoliosis would be directly due to a deficiency in tryptophan, even if the actual involved mechanism is not yet elucidated. This experiment showed that a dietary deficiency in one amino acid could have high implications in larval development.

\subsection{Effect of peptides}

Dietary incorporation of peptides is beneficial for fish larval development. Indeed, it has been demonstrated that partial replacement of whole protein by protein hydrolysates in the diet fed to larvae led to improvement of growth and survival both in freshwater and sea water species. Incorporation of casein hydrolysate led to a better survival in carp (Szlaminska et al., 1993) as in sea bass larvae (Cahu and Zambonino Infante, 1995). Incorporation of fish protein hydrolysate seems especially advantageous. Experiments have been conducted by substituting whole fish protein by fish hydrolysate constituted by peptide chains of 10 to 20 amino acids (CPSP-G®, Sopropèche, France) (Cahu et al., 1999) or fish hydrolysate constituted by di- and tri-peptides (Zambonino Infante et al., 1997) in diet fed to sea bass larvae. It appeared that a moderate level of hydrolysate, $20 \%$ substitution to fish meal, induced growth and survival improvement in sea bass larvae. The higher substitution levels depressed growth and survival as it was also reported in sea bream larvae fed diet incorporating hydrolysed squid meal (Kolkovski and Tandler, 2000). But incidence of skeletal malformations, assessed by examinating larvae at day 40, after feeding compound diets for 31 days, significantly decreased with increasing level of hydrolysate in diet. For example, only $2 \%$ of larvae fed diet incorporating 58\% hydrolysate (CPSP) in substitution to fish meal exhibited skeletal (spinal 
or jaw) malformation, while the malformation rate reached 13\% in group fed diet without hydrolysate (Fig. 3). However, weight at day 40 was 50\% lower in the group fed the diet incorporating 38\% hydrolysate, compared to the group fed the diet without hydrolysate. Incorporation of di- and tri-peptide instead of CPSP led to similar results: malformation rate decreased with hydrolysate incorporation.

The specific ability of larvae to digest peptides could explain the beneficial effect of hydrolysate on larval development. Indeed, some cytosolic enzymes, peptidases are largely expressed during young stages. It has been shown, in particular, that peptidase hydrolysing the dipeptide leucine-alanine exhibit a 10-fold higher activity in 15-day-old sea bass compared to 40 day old sea bass larvae (Cahu and Zambonino Infante, 2001). Moreover, amino acid transporters appear at different time during ontogenesis in vertebrates including fish (Buddington, 1992). Therefore, it can be assumed that the supply in some essential amino acids in larvae is ensured by peptides, which have their own transporters. This can explain the efficiency of dietary peptides in supporting harmonious development in larvae and particularly the skeletal development. Nevertheless, dietary incorporation of high hydrolysate levels has a negative effect on growth. Indeed, high dietary hydrolysate level led to a fast flow of peptides and free amino acids through the digestive system (Cahu et al., 1999, Kolkovski and Tandler, 2000).

\section{Effect of vitamins}

\subsection{Retinoic acid}

The teratogenic effect of retinoic acid, a compound related to vitamin A, is now well documented in vertebrates (Ross et al., 2000). Retinoic acid acts on the expression of the genes of Hox family, which are involved in the formation process of antero-posterior axis (Conlon, 1995). A role of vitamin A in skeletal malformation of larvae produced in hatchery is suspected since some years (Takeuchi et al., 1998). Indeed, the level of vitamin A in emulsion for Artemia enrichment can induce very high vitamin A concentration in Artemia fed to young larvae.

Dedi et al. (1995) conducted an experiment by feeding six groups of Japanese flounder larvae, Paralichtys olivaceus, with Artemia enriched with increasing vitamin A levels. Vitamin A 
concentration in Artemia was: 1, 45, 416, 585, 840, $1280 \mathrm{IU} / \mathrm{g}$ dry matter. Survival was slightly higher in fish fed high vitamin A levels at day 40. At the opposite, high vitamin A content resulted in lower body weight: $87 \mathrm{mg}$ in group fed the lower vitamin A level, and 54 mg in group fed the highest vitamin A level. But the most important effect was on larval deformities. High vitamin A level resulted in higher incidence of bone deformities, such as vertebral curvature, central fusion and compression of vertebra. Almost all the fish in the group fed the highest vitamin A levels showed bone deformities, and almost all the 37 vertebrae were abnormal in these fish (Fig. 4). Incidence of deformity was low in groups fed 1 or $45 \mathrm{IU} / \mathrm{g}$ diet dry matter, and in these groups, the malformations occurred only in vertebrae 7 to 10, corresponding to the body cavity. By comparison with results obtain in guinea pig (Wolbach, 1947), the authors assumed that the hypervitaminosis in fish fed Artemia enriched with high vitamin A levels probably accelerated cartilage maturation, degeneration of the epiphyseal cartilage cells and concurrently rapid replacement by bone. Excess of vitamin A accelerated the formation and growth of the vertebra leading to skeletal abnormalities. The authors recommended a concentration inferior to 20 mg vitamin A per 10 liters (2000 IU/liter) in Artemia culture to limit bone deformities in fish larvae.

Furthermore, the effect of Artemia enriched with four kinds of vitamin A compounds (retinol, retinyl palmitate, retinyl acetate, and all-trans RA(ATRA)) on the vertebral deformity of flounder was investigated, to understand whether vitamin A exerts teratogen effects as original form or their derivatives (Takeuchi et al.,1998). The fish fed Artemia enriched with these retinoids, especially (retinoic acid) RA showed severe vertebral deformity. Further, Haga et al. (1999) examined the effect of RA on the occurrence of vertebral deformity by feeding Artemia enriched three different levels of RA $\left(10 \times 10^{3}, 50 \times 10^{3}, 100 \times 10^{3} \mu \mathrm{g}\right.$ RA). They observed that vertebral deformity in flounder occurred in a dose-dependent manner. RA induced vertebral deformities in a similar pattern as induced by various retinoids, suggesting that RA is a critical factor causing vertebral deformity in juvenile flounder.

Recently, Haga et al (in press) also reported that ATRA administered during the A-B stages (4-8 days after hatching) caused a high number of abnormal vertebrae mainly in the caudal area. These results indicate that the effect of ATRA is development stage specific in flounder larvae and also suggest that morphological abnormality in flounder was induced by ATRA accumulated in live foods (rotifers: 13mg/g; Artemia: $1.6 \mathrm{mg} / \mathrm{g}$ ), especially during the A-B stages. 
The molecular control of the process of skeletal formation is just beginning to be understood in fish. Development of the pharyngeal skeleton involves activation of some genes, such as Hox genes and sonic hedgehog (shh) (Suzuki et al., 1998, Suzuki et al., 1999), known to be a transcriptional factor. It has been demonstrated that the immersion of flounder embryos in retinoid acid solution depresses expression of shh and Hoxd-4 genes, inducing severe abnormal pharyngeal cartilage formation (Suzuki et al. 1999). Moreover, Haga et al. (2001) demonstrated that immersion of 8-day-old flounder larvae in different retinoic acid receptors (RAR/RXR) resulted in characteristic malformations in the lower jaw. The authors concluded that each RAR/RXR receptor has a different role in lower jaw development during postembryonic stage.

So the teratogenic effect of retinoic acid observed in embryonic and postembryonic stage was explained by a depression of shh expression. Moreover, it has been shown that shh expression is reinduced in Xenopus, long after embryonic development, by thyroid hormone to induce organogenesis (Stolow and Shi, 1995). Shh is involved in development of various skeletal systems. So it appears possible that shh acts in skeletal formation not only at embryonic and postembryonic stages but also at metamorphosis stages during flounder development (Suzuki et al., 1999).

\subsection{Ascorbic acid}

Ascorbic acid has a large implication in several physiological function in vertebrates, such as growth, skeletal development, resistance to toxicants and stress, and immunoactivity.... Dabrowski et al. (1988) reported a deficiency in dietary ascorbic acid induced gill arch pathology and caudal fin erosion in carp larvae. Merchie et al. (1995) showed that high ascorbic acid levels increased growth rate and stress resistance in African catfish larvae. Moreover, the content in ascorbic acid rapidly declines during embryonic development in fish (Cowey et al., 1985). Ascorbic acid supplied by diet is crucial for fish larvae development, since most of the species are unable to synthesise this vitamin.

Nevertheless, there is little data on vitamin C requirement of first feeding larvae. Some data are available for larvae of fresh water fish, which can be fed with compound diet. The minimum dietary concentration for optimal growth and survival in carp larvae has been found to be 45 mg ascorbic acid equivalent per kg dry matter (Gouillou-Coustans et al., 1998). Ascorbic acid requirement has been precisely evaluated from weaning in marine fish larvae, when compound diet begin to be utilisable. Twenty mg ascorbic acid equivalent per kg dry 
matter are convenient in weaning diet for 35-day-old European sea bass and turbot (Merchie, 1996).

So, the ascorbic acid concentration in non-enriched Artemia, which can reach up to $500 \mathrm{mg}$ equivalent ascorbic acid per gram dry matter (Merchie et al., 1996), is generally considered to be sufficient to meet the nutritional requirements of developing larvae. Nevertheless, Gapasin et al. (1998), reported that the incidence of opercular abnormalities was $50 \%$ lower in milkfish larvae fed rotifer and Artemia enriched with highly unsaturated fatty acid and ascorbic acid, compared to fish fed rotifers and Artemia enriched only with highly unsaturated fatty acids. These opercular abnormalities, associated with distortion of gill filament cartilages, is characteristic of scorbutic fish (Lim and Lowell, 1978; Soliman et al., 1986) and is the result of a de-calcification (Dabrowski et al., 1990). Interestingly, neither growth nor survival was improved by this ascorbic acid enrichment. So, the role of ascorbic acid in marine fish larvae development needs further investigations, since Dabrowski et al. (1996) showed that the sensitivity to ascorbic acid deficiency is higher in larval stages than in juveniles in channel catfish.

\section{Conclusions}

Recent studies (for review see Cahu and Zambonino, 2001) have shown that nutritional requirements to sustain survival and growth in marine fish larvae are slightly different to those of juveniles. These components, mainly phospholipids, peptides and vitamins have a major influence on skeletal formation. Description of the biological effects of these components is essential, and the understanding of the action of these components at the molecular level will allow to improve quality of hatchery reared larvae. Compound diets, usable from first feeding in some marine fish larvae, are now formulated. The major aim of the studies conducted now in larval nutrition is to improve larvae quality.

\section{Acknowledgements}

The authors thank all the team of the "Laboratory of Aquaculture \& Artemia Reference Center” for the organization of Larvi'01 Symposium and for their work for the publication of this “Aquaculture” special issue. 


\section{References}

Akiyama, T., Murai, T., Nose T., 1986. Oral administration of serotonin against spinal deformity of chum salmon fry induced tryptophan deficiency. Bull. Jap. Soc. Scient. Fish. 52, 1249-1254.

Andrades, J., Becerra, J., Fernandez-Llebrez, P., 1996. Skeletal deformities in larval, juvenile and adult stages of cultured gilthead sea bream (Sparus aurata L.). Aquaculture 141, 111.

Aragão, C., Conceição, L.E.C., Fyhn, H.J. Dinis, M.T., 2001. Amino acid profiles of sea bream (Sparus aurata) and sole (Solea senegalensis) during first feeding: are currently used diets imbalanced in amino acids? Larvi’01- Fish and Shellfish larviculture symposium. Hendry C.I., Van Stappen G., Wille M. and Sorgeloos P. (Editors). European Aquaculture Society, Special publication N³0, Oostende, Belgium, 32-35.

Berridge, M.J., Irvine, R.F., 1989. Inositol phosphates and cell signalling. Nature 341, 197205.

Boglione, C., Gagliardi, F., Scardi, M., Cautaudella, S., 2001. Skeletal descriptors and quality assessment in larvae and post-larvae of wild-caught and hatchery-reared gilthead sea bream (Sparus aurata L. 1758). Aquaculture 192, 1-22.

Buddington, R.K., 1992. Intestinal nutrient transport during ontogeny of vertebrates. Am. J. Physiol. 32, R503-R509.

Cahu, C.L., Zambonino Infante, J.L, 1995. Effect of the molecular form of dietary nitrogen supply in sea bass larvae: Response of pancreatic enzymes and intestinal peptidases. Fish Physiol. Biochem. 14, 209-214.

Cahu, C.L., Zambonino Infante, J.L., Quazuguel, P., Le Gall, M.M., 1999. Protein hydrolysate vs. fish meal in compound diets for 10-day old sea bass Dicentrarchus labrax larvae. Aquaculture 171, 109-119.

Cahu, C.L., Zambonino Infante, J.L, 2001. Substitution of live food by formulated diets in marine fish larvae. Aquaculture 200, 161-180.

Cahu, C.L., Zambonino Infante, J.L., Barbosa, V. Phospholipid level in dietary lipid fraction is determining for sea bass (Dicentrarchus Labrax) larval development. Br. J. Nutr., in press.

Chatain, B., 1994. Abnormal swimbladder development and lordosis in sea bass (Dicentrarchus labrax) and sea bream (Sparus aurata). Aquaculture 119, 371-379. 
Conceição, L.E.C, van der Meeren, T., Verreth, J.A.J., Evjen, M.S., Houlihan, D.F., Fyhn, H.J., 1997. Amino acid metabolism and protein turnover in larval turbot (Scophthalmus maximus) fed natural zoopankton or Artemia. Mar. Biol. 129:,255-265.

Conlon, R., 1995. Retinoic acid and pattern formation in vertebrates. TIG 11, 314-319.

Cowey C.B., Bell, J.G., Knox, D., Farser, A., Youngson, A., 1985. Lipid and lipid antioxydant systems in developing eggs of salmon (Salmo salar). Lipids 20, 567-572.

Dabrowski, K., Hinterleitner, S., Sturmbauer, C., El-Fiky, N. Wieser, W., 1988. Do carp larvae require vitamin C? Aquaculture 72, 295-306.

Dabrowski, K., El-Fiki, N., Kock, G., Frigg, M., Wieser, W., 1990. Requirement and utilization of ascorbic acid and ascorbic sulfate in juvenile rainbow trout, Salmo gairdneri Richardson. Aquaculture 91, 317-337.

Dabrowski, K., Moreau, R, El-Saidy, D., 1996. Ontogenetic sensitivity of channel catfish to ascorbic acid deficiency. J. Aquatic Anim. Health 8, 22-27.

Dedi, J., Takeushi, T., Seikai, T. Watanabe, T., 1995. Hypervitaminosis and safe levels of vitamin A for larval flounder (Paralichtys olivaceus) fed Artemia nauplii. Aquaculture 133, 135-146.

Divanach, P., Boglione, C., Menu, M., Kounoundouros, G., Kentouri, M., Cataudella S., 1996. Abnormalities in finfish mariculture: an overview of the problem, causes and solutions. Sea bass and Sea bream culture: problems and prospects. Verona, Italy, October 16-18. European aquaculture Society, Oostende, Belgium, pp. 45-66.

Estévez, A., Mc Evoy, L.A., Bell, J.G., Sargent, J.R., 1999. Growth, survival, lipid composition and pigmentation of turbot (Scophtalmus maximus) larvae fed live prey enriched in arachidonic and eicosapentaenoic acids. Aquaculture 180: 321-343.

Furuita, H., Takeuchi, T. Uematsu, K., 1998. Effects of eicosapentaenoic and docosahexaenoic acids on growth, survival and brain development of larval Japanese flounder (Paralichtys olivaceus). Aquaculture 161, 269-279.

Fushimi, H., 2001. Production of juvenile marine finfish for stock enhancement in Japan. Aquaculture 200, 33-53.

Gapasin, R.S.J., Bombeo, R., Lavens, P., Sorgeloos, P. Nelis, H., 1997. Enrichment of live food with essential fatty acids and vitamin C: effects on milkfish (Chanos chanos) larval performance. Aquaculture 162, 269-286.

Gapasin, R.S.J., Duray, M.N., 2001. Effects of DHA-enriched live food on growth, survival and incidence of opercular deformities in milkfish (Chanos chanos). Aquaculture 193, 49-63. 
Geurden, I., Charlon, N., Marion, D. and Bergot, P., 1997. Influence of purified soybean phospholipids on early development of common carp. Aquacult. Int. 5, 137-149.

Geurden, I., Marion, D., Charlon, N., Coutteau, P., Bergot, P., 1998. Comparison of different soybean phospholipidic fraction as dietary supplements for common carp Cyprinus carpio larvae. Aquaculture 161, 213-223.

Gouillou-Coustans, M.F., Bergot, P., Kaushik, S.J., 1998. Dietary ascorbic acid needs of common carp (Cyprinus carpio) larvae. Aquaculture 161, 453-461.

Haga, Y., Takeuchi, T., Seika,i T.1999. Effect of retinoic acid on larval Japanese flounder, Paralichthys olivaceus, reared on Atremia nauplii. Suisanzoshoku, 47:559-566.

Haga, Y., Takeuch,i T., Seikai, T. Influence of all trans retinoic acid on pigmentation and skeletal formation in larval Japanese flounder. Fisheries Sci, in press.

Haga Y., Suzuki T., Kagechika H. and Takeuchi T. 2001. Retionoid agonits induce lower jaw deformity in postembryonic development of flounder, Paralichtys olivaceus. $14^{\text {th }}$ Int. Congress of Developmental Biology, July 8-12, Kyoto, Japan.

Johnson, D.W., Katavic, I., 1984. Mortality, growth and swim bladder stress syndrome of sea bass (Dicentrarchus labrax) larvae under varied environmental conditions. Aquaculture 38, 67-78.

Kanazawa, A., Teshima, S., Inamori, S., Iwashita, T., Nagao, A., 1981. Effects of phospholipids on growth, survival rate and incidence of malformation in the larval Ayu. Mem. Fac. Fish. Kagoshima Univ. 30, 301-309.

Kanazawa, A., Teshima, S., Tobayashi, T., Takae, M, Iwashita, T. Uehara, R., 1983. Necessity of dietary phospholipids for growth of larval Ayu. Mem. Fac. Fish. Kagoshima Univ. 32, 115-120.

Kolkovski, S., Tandler, A., 2000. The use of squid protein hydrolysate as a protein source in microdiets for gilthead seabream Sparus aurata larvae. Aquacult. Nutr. 6, 11-17.

Koven, W, Barr, Y., Lutzky, S., Ben-Atia, I., Weiss, R., Harel, M., Behrens, P., Tandler, A., 2001. The effect of dietary arachidonic acid (20: 4n-6) on growth, survival and resistance to handling stress in gilthead seabream (Sparus aurata). Aquaculture 193, 107-122.

Jump, D. B., Clarke, S. D., 1999. Regulation of gene expression by dietary fat. Annu. Rev. Nutr. 19, 63-90.

Lim, C., Lovell, R.T., 1978. Pathology of the vitamin C deficiency syndrome in channel catfish (Ictalurus punctatus). J. Nutr. 108, 1137-1146. 
Madsen, L., Dalsgaard I., 1999. Vertebral column deformities in farmed rainbow trout (Oncorhynchus mykiss). Aquaculture 171, 41-48.

Merchie, G., Lavens, P. Dhert, Ph., Pector, R., Mai Soni, A.F., Abbes, M., Nelis, H., Ollevier, F., De Leenheer, A., Sorgeloos, P., 1995. Live food mediated vitamin C transfer to Dicentrarchus labrax and Clarias gariepinus. J. Appl. Ichthyol. 11, 336-341.

Merchie, G., Lavens, P. Dhert, Ph., Garcia Ulloa Gomez, M., Nelis, H., De Leenheer, A., Sorgeloos, P., 1996. Dietary ascorbic acid requirements during the hatchery production of turbot. J. Fish Biol. 49, 573-583.

Rønnestad, I., Thorsen, A., Finn, R.N., 1999. Fish larval nutrition: a review of recent advances in the roles of amino acids. Aquaculture 177, 201-216.

Ross A.S., McCaffery P.J., Drager U.C., De Luca, L.M. 2000. Retinoids in embryonal development. Pysiological Reviews 80, 1021-1054.

Reitan, K.I., Rainuzzo, J.R., and Olsen, Y., 1994. Influence of lipid composition of live feed on growth, survival and pigmentation of turbot larvae. Aquacult. Int. 2, 33-48.

Sadler, J., Pankhurst, P.M. King, H.R., 2001. High prevalence of skeletal deformity and reduced gill surface area in triploid Atlantic salmon (Salmo salar L.). Aquaculture 198, 369-386.

Sargent, J., McEvoy, L., Estevez, A., Bell, G., Bell, G., Henderson, J., Tocher, D., 1999. Lipid nutrition of marine fish during early development : current status and future directions. Aquaculture 179, 217-229.

Shields, R. J., Bell, J.G., Luizi, F.S., Gara, B., Bromage, N.R. Sargent, J., 1999. Natural copepods are superior to enriched Artemia nauplii as feed for halibut larvae (Hippoglossus hippoglossus) in terms of survival, pigmentation and retinal morphology: relation to dietary essential fatty acids. J. Nutr. 129, 1186-1194.

Soliman, A.K., Jauncey, K., Roberts, R.J., 1986. The effects of varying forms of dietary ascorbic acid on the nutrition of juvenile tilapias (Oreochromis niloticus). Aquaculture 52, $1-10$.

Stolow, M.A., Shi, Y.B. 1995. Xenopus sonic hedgehog as a potential morphogen during embryogenesis and thyroid hormone-dependent metamorphosis. Nucleic Acids Res. 23, 2555-2562.

Suzuki, T., Oohara, I., Kurokawa, T., 1998. Hoxd-4 expression during pharyngeal arch development in flounder (Paralichtys olivaceus) embryos and effects of retinoic acid on expression. Zoological Science 15, 57-67. 
Suzuki, T., Oohara, I., Kurokawa, T., 1999. Retinoic acid given at late embryonic stage depresses sonic hedgehog and Hoxd-4 expression in the pharyngeal area and induces skeletal malformation in flounder (Paralichtys olivaceus) embryos. Develop. Growth Differ. 41, 143-152.

Szlaminska, M., Escaffre, A.M., Charlon, N., Bergot, P., 1993. Preliminary data on semi synthetic diets for goldfish Carassius auratus L. larvae. In: Kaushik, S.J. and Luquet, P. (Eds), Fish Nutrition in Practice, Edition INRA, Paris, Les Colloques n61: 606-612.

Takeuchi, T., 2001. A review of feed development for early life stages of marine finfish in Japan. Aquaculture 200, 203-222.

Takeuchi, T., Dedi, J., Haga, Y., Seikai, T., Watanabe, T.1998. Effect of vitamin A compounds on bone deformity in larval Japanese flounder (Paralichthys olivaceus) . Aquaculture 169, 155-165.

Watanabe, T., Kiron, V., 1994. Prospects in larval fish dietetics. Aquaculture 124, 223-253.

Wolbach, S.B., 1947. Vitamin A deficiency and excess in relation to skeletal growth. J. Bone Jt. Surg. 29, 171-192.

Zambonino Infante, J.L., Cahu, C.L., Péres, A., 1997. Partial substitution of di- and tripeptides for native proteins in sea bass diet improves Dicentrarchus labrax larval development. J. Nutr. 127, 608-614. 
Figure 1. Percentage of skeletal malformation observed in 40-day-old sea bass fed from first feeding with different phospholipid concentrations. Results are expressed as means \pm SD. Means with different superscript letters are significantly different $(P<0.05)$. From Cahu et al. (in press).

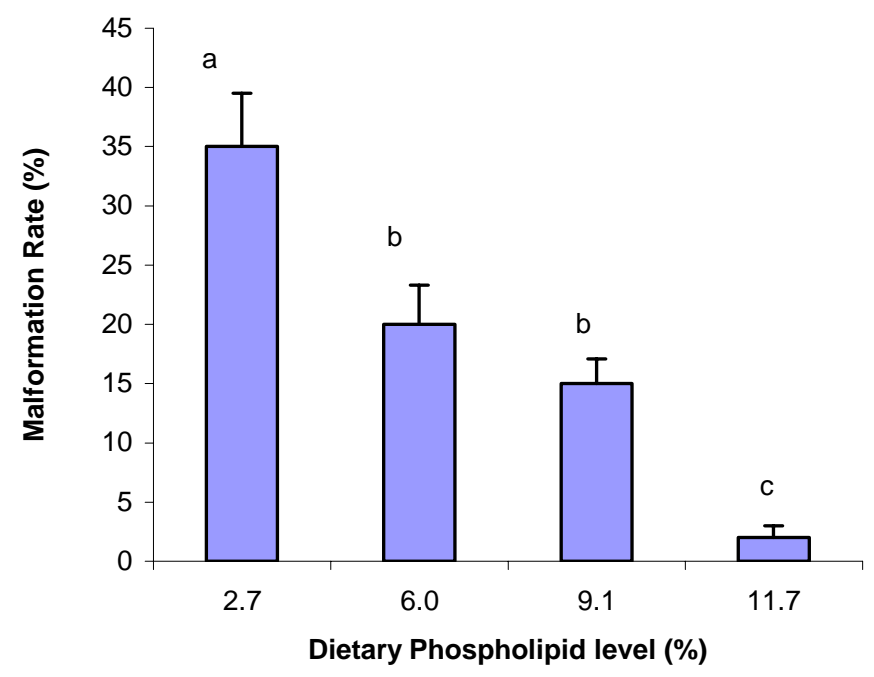

Figure 2. Effect of tryptophan deficient diet fed to chum salmon larvae during the 4 first weeks of their life. Fry were after fed during three weeks with either the same diet, with serotonin supplemented diet or tryptophan supplemented diet. From Akiyama et al. (1986)

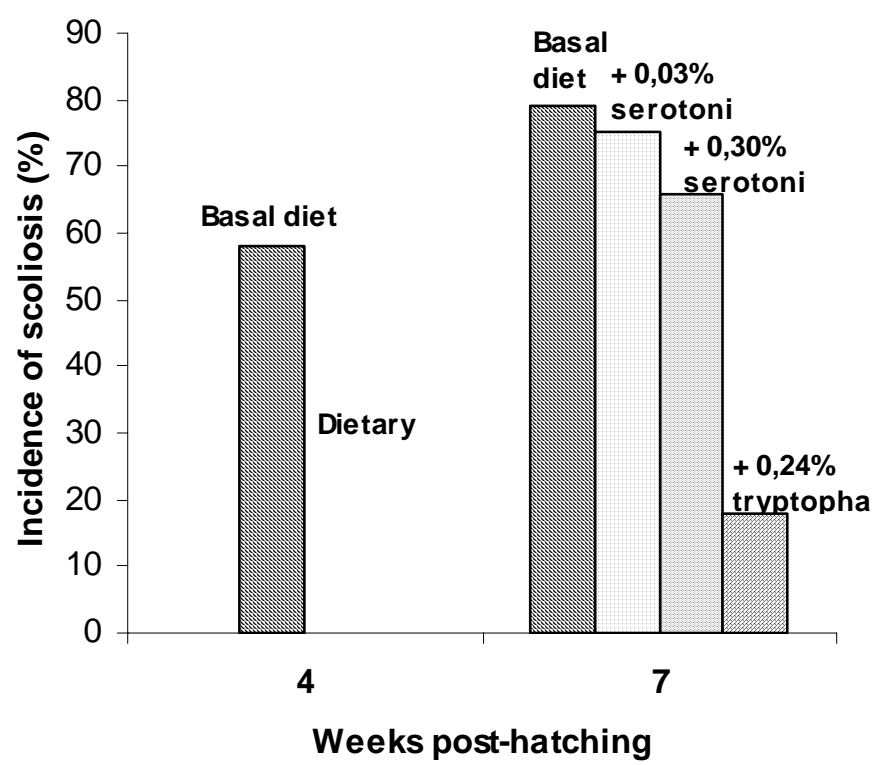


Figure 3. Percentage of skeletal malformation observed in 40-day-old sea bass fed for 4 weeks with compound diets incorporating different concentrations of protein hydrolysates. Diets P0, P20, P40 incorporated 0, 20 and 40\% of total protein fraction as di- and tripeptides. Diets H0, H19, H38 and H58 incorporated 0, 19, 38 and 58\% of total protein fraction as peptides chains of 20 amino acids. Results are expressed as means \pm SD. Means with different superscript letters are significantly different $(P<0.05)$. From Zambonino et al. (1997) and Cahu et al. (1999).
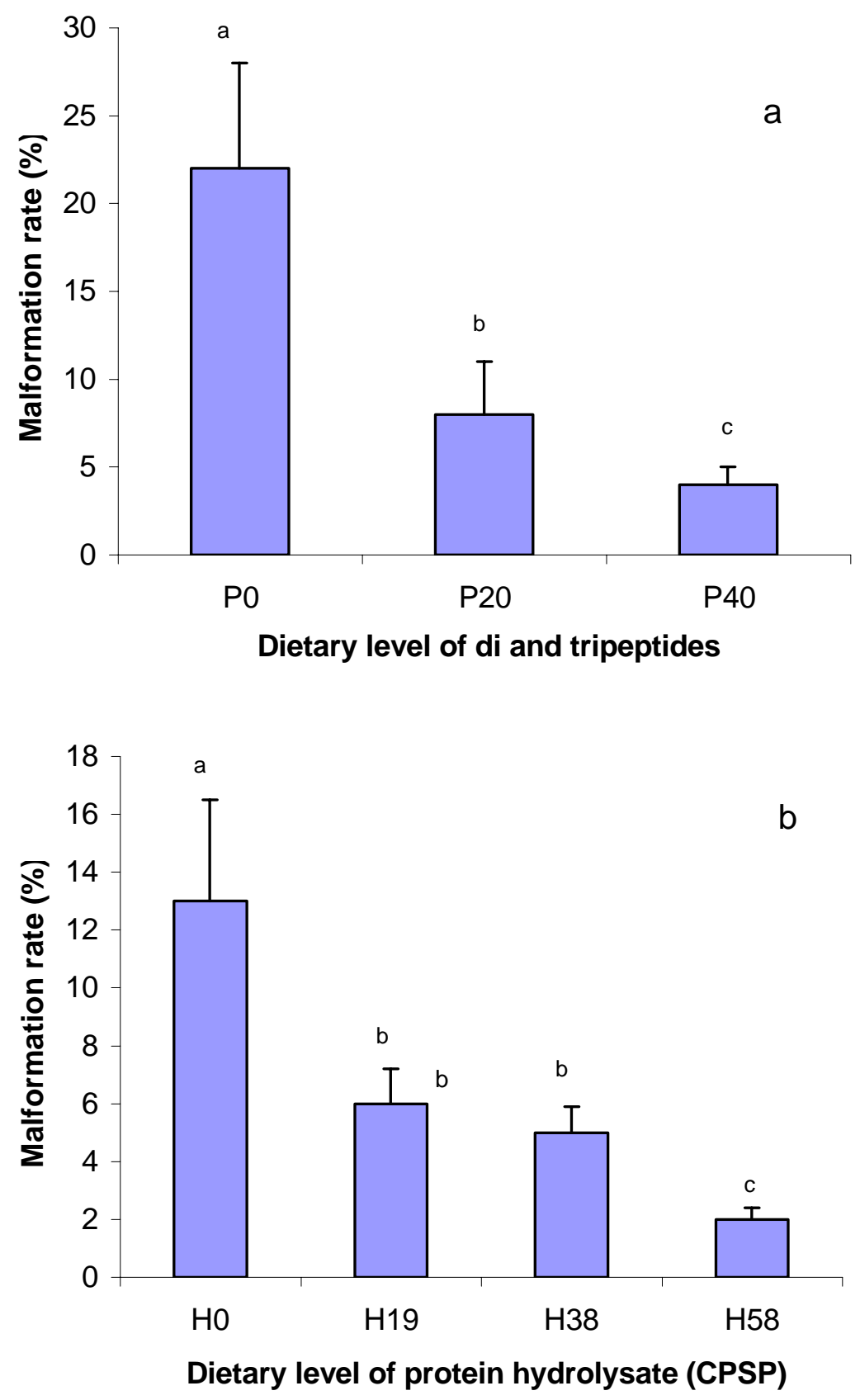
Figure 4: Percentage of fry exhibiting vertebral deformities and weight in Japanese flounder fed Artemia enriched with different levels in retinoic acid. From Dedi et al. (1995).

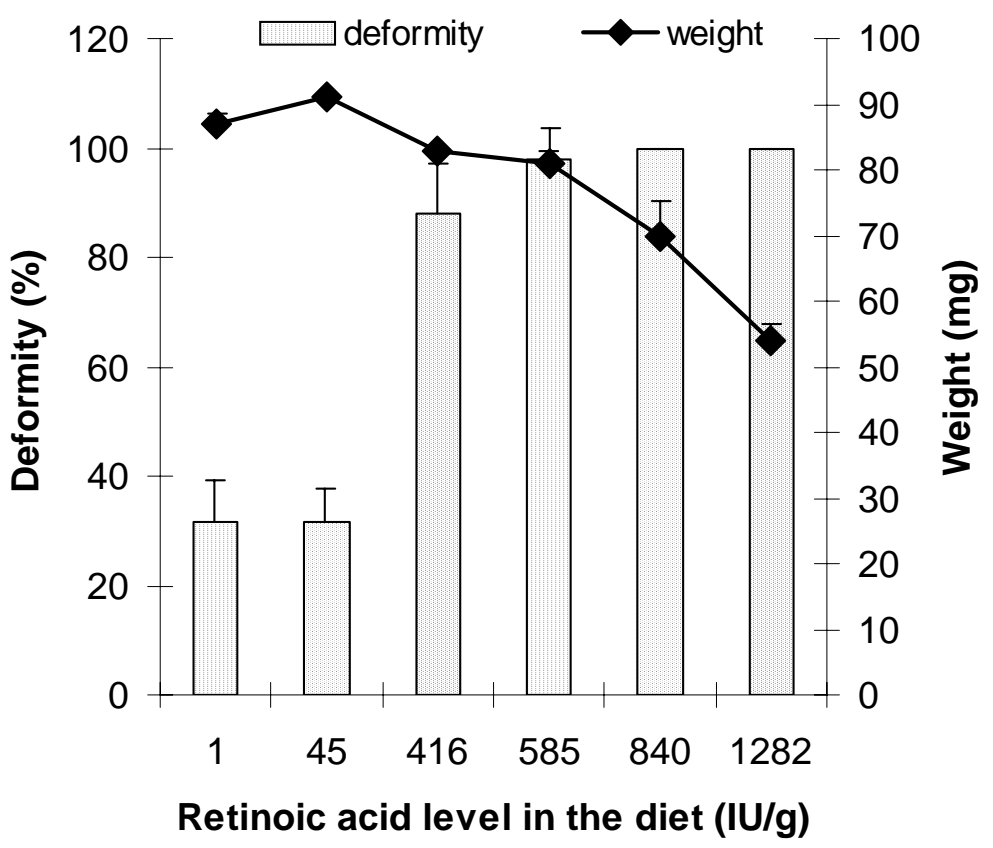


TABLE 1

Added lipid and composition of the lipid fraction in the experimental diets. From Cahu et al. (in press)

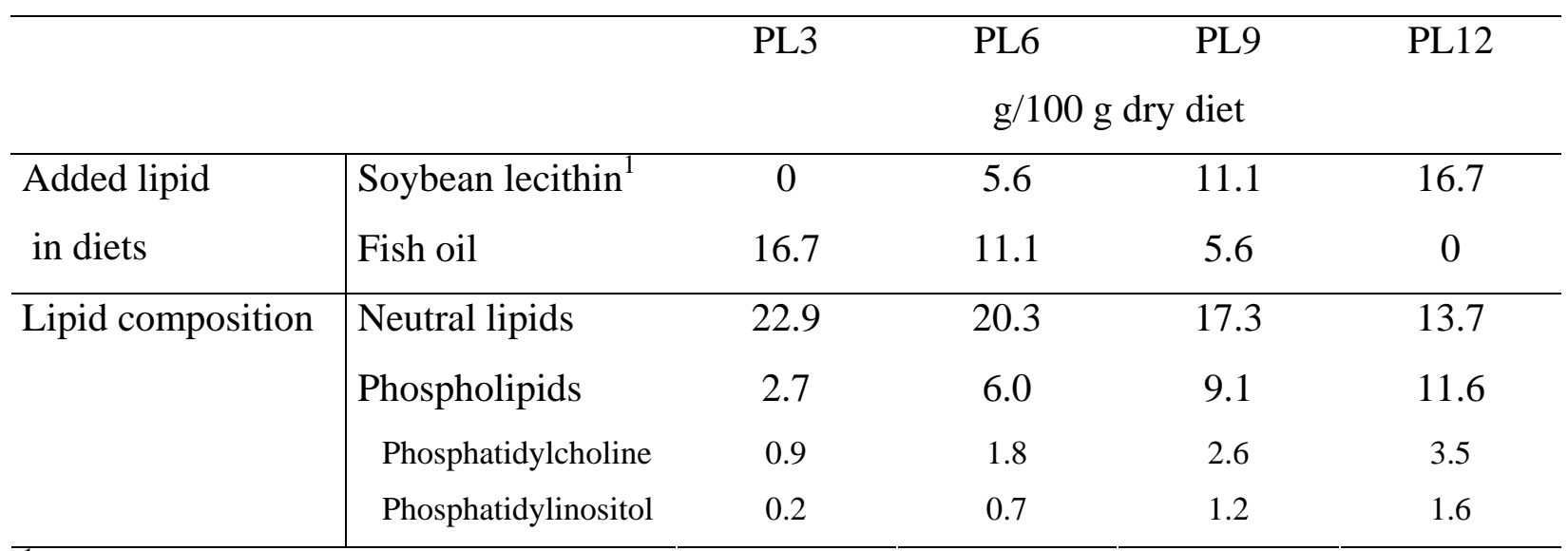

${ }^{1}$ Soybean lecithin contains $62 \%$ phospholipid, including 26\% phosphatidylcholine, $20 \%$ phosphatidylethanolamine and $14 \%$ phosphatidylinositol. 